\title{
The Difference between the Effectiveness of Authentic and Pedagogical Films in Learning Vocabulary among Iranian EFL Students
}

\author{
Somayeh Soltani (Corresponding author) \\ Department of English Language and Literature Larestan Branch, \\ Islamic Azad University, Larestan, Iran \\ E-mail: sm.soltani87@gmail.com \\ Afshin Soori \\ Department of English Language and Literature Larestan Branch, \\ Islamic Azad University, Larestan, Iran \\ E-mail: afshin_soori@yahoo.com
}

Doi:10.7575/aiac.alls.v.6n.1p.199

Received: 08/10/2014

URL: http://dx.doi.org/10.7575/aiac.alls.v.6n.1p.199

Accepted: 25/12/2014

\begin{abstract}
This study tried to investigate the effectiveness of authentic and pedagogical films with English and Persian subtitles in learning vocabulary. Moreover, the role of these two types of subtitles and the films with no subtitles were investigated. To conduct the study, 30 Iranian EFL students were selected based on the results of an Oxford Placement Test and were assigned in two experimental groups as authentic and pedagogical groups. The students were given twelve sessions as treatment. Then, the researcher administered a post-test at the end of the treatment period. The post-test was a multiplechoice test with 25 items. To answer the research questions statistical analysis was performed. The results of t-test showed that the students in authentic group had a better performance than the students in the pedagogical group in vocabulary learning. Regarding the findings of One-way ANOVA and post-hoc Tuckey test, revealed that the students who received films with English subtitles had a better performance in comparison to groups of students who watched films with Farsi subtitles or those watched films with no subtitles.
\end{abstract}

Keywords: Subtitles, pedagogical, authentic, films, EFL students, vocabulary learning

\section{Introduction}

One of the essential part or perhaps the most difficult part of learning a second or foreign language is learning vocabulary. Unlike, learning grammar which is rule based, vocabulary learning is a matter of remembering (Thornbury, 2004). Recently, some Iranian researchers have paid attention to the effectiveness of using movies as helpful instructional purposes especially for learning vocabulary. Among the researchers, Hayati \& Mohammadi (2009) and Talavan (2007) investigated the relationship between improving listening skill and watching movies. However, there is a limited number of studies (e.g. Alipour, Gorjian \&Gholampour Kouravand, 2012) on the impacts different types of movies like pedagogical and authentic movies. Moreover, the difference in the effectiveness of English and Farsi subtitles in learning vocabulary. The aim of the present study is to identify which one, pedagogical or authentic movies with English and Persian subtitles are more effective in learning vocabulary.

\section{Review of Related Literature}

One of the most important parts of the learner's educational life is learning vocabulary. According to Alipour, Gorjian \&Gholampour Kouravand (2012), teachers are aware of this fact that word-for-word translation is possible. Gorjian, Pazhakh \& Naghizadeh (2012) believe that learning a foreign language is nothing more than using new words. To Kim \& Gilman (2008) some strategies like word lists used for vocabulary learning. In this case, the "new words which are presented with their translations and these strategies are outdated and irrelevant to students who are accustomed to visual stimuli" Gorjian \&Gholampour Kouravand, 2012, p. 735). Thus, curriculum designers and language developers need to reconsider the role of multimedia for learning vocabulary (Gorjian, Alipour \& Saffarian, 2012).

Teachers usually take advantage of both authentic and pedagogical materials to motivate and thrill the students in the language classroom.

\section{Authentic and Pedagogical Materials in Language Learning}

Mishan (2005) points to the entertainment and enjoyment in the language classroom in which the teacher uses a movie for the learners. Mishan (2005, as cited in Alipour, et al., 2012) believes that "film is the one that is designed to appeal most directly and fully to our emotions and also the one most clearly entrenched in learners' minds as a medium of entertainment" (p.734). This means that using film in a language classroom has an important effect on learning a second 
or foreign language. Authentic materials are defined by Koolstra and Beentjes (1999) as appropriate and quality materials which are compatible with the learners' needs, interests and play important roles in meaningful communication. The results of a study by Chapple and Carties (2003) revealed using film can be an appropriate teaching material in context-based instruction approaches in EFL classrooms. Chapple and Carties (2003) came to the conclusion that films are valuable pedagogical materials and can provide the EFL learners with rich source of context and vocabulary. To Reese and Davie (1987), visual illustrations can be more effective when they come with scripts. Reese (1984) considers no effect for subtitles in understanding the news stories. One reason may refer to the limitations of single-channel processing, and the abilities of human beings in attending only one channel at a time. In a study by Mayer, Heinser, and Lonn (2001), the English native speakers who watched the animation and listened to a concurrent narration in L1were able to retain more information from the narration in comparison to those who also received captions as a third modality. They came to the conclusion that captions can be distracting because they carry the same information, "which follows the redundancy principle" (Alipour, et al., 2012, p.734). In this case, to Cognitive load theory, non-captioned videos can be processed more easily in comparison to captioned videos. In a study, Koolstra and Beentjes (1999) tried to investigate the impact of the similarity between foreign and native languages on language acquisition. In this case, the researchers exposed the participants to subtitled TV programs with some soundtracks which were similar or dissimilar to their first language. The results of their study revealed that language acquisition was better with programs with soundtracks in languages which were similar to the native language.

It seems that films included captions can provide a rich context for acquisition of a foreign language. "It is also argued that viewers are generally quite motivated to understand what is shown and said on films when the subtitles are provided (Danan, 2004as cited in Alipour, et al., 2012, p.735). The findings of another study by Hayati \& Mohammadi, (2009), revealed that films with Persian subtitles facilitated recognition of English words by supplying the meaning of the context in the student's first language. Vocabulary recognition by the students through watching films in Spanish with English subtitles and watching the same films with Spanish subtitles was investigated by Stewart and Pertusa (2004). They found that intralingual subtitles can be more effective and can increase vocabulary recognition.

The impact of modality of the acquisition of vocabulary on Russian learners was investigated by Sydorenko(2010). The findings of this study revealed that the groups who received captions had better score on written than on aural recognition. Following the related literature, the research question is as follows:

What is the difference between the effects pedagogical and authentic English movies on Iranian students' vocabulary learning?

\section{Methodology}

\subsection{Participants}

The participants of this study were 30 Iranian EFL students with a range of 20 to 28 who were studying in an English institute in Shiraz, Iran. These participants were selected from a population of 60 students. To select two homogeneous groups of students, the researcher administered an Oxford Placement Test. In terms of the results of the test, the students were ranked from the higher to lower. To this purpose, the first 30 students whose scores were higher were selected. After that, the students were assigned into two experimental groups (pedagogical and authentic). Each group contained 15 students. It was about two years that he students were studying English in the institute.

For the first experimental group (pedagogical group), a pedagogical film was watched in three parts. In the first four sessions the students watched the first part of the film with Farsi subtitles. Then, they watched the second part of the film with English subtitles for the next four sessions. In the last four sessions, the students watched last part of the movie with no subtitles.

The second experimental group (authentic group) included 15 students. Like the students in pedagogical group, the students in authentic group watched the authentic film in three parts. During the first four sessions the students watched the film with Farsi subtitles. For the next four sessions, the students watched the film with English subtitles. Finally, they watched the last part of the film without any subtitles.

\subsection{Instruments}

\section{Tests}

A sample of Oxford Placement Test (OPT) was administered to students to choose two homogenous groups in terms of their language proficiency. The OPT included 60 multiple-choice items. The students answered the questions in 50 minutes.

To identify the impact of pedagogical film with subtitles on the students' vocabulary learning, three post-tests were administered. Each test included 25 multiple-choice items on English vocabulary. Each post-test was given to students after each four sessions. The students answered the questions in 15 minutes. The vocabulary used for the post-tests were taken from the films with and without subtitles. The total score was 25 if a participant answered all the items correctly. KR-21 method was used to check the reliability of each test.After twelve sessions, another post-test was administered to two groups and the results were compared to identify the impact of watching both pedagogical and authentic films on the students' vocabulary learning. 


\section{Films}

Since each term in the institute continued for 12 sessions, the teacher could select one film for each class. The classes in the institute held 90 minutes each session. Since the time of each film was about one hour and half, the teacher was able to apply one film for each class. The films were supposed to be broadcasted included 3 parts. The first part was with Farsi subtitles, the second part was with English subtitles, and the third part had no subtitles. The researcher selected films which were appropriate and fun for both authentic and pedagogical groups.

\subsection{Procedure}

The current study was conducted in an English institute in Jahrom,Iran. To be sure of homogeneity among the students, the researcher divided them randomly into two groups. The students in the first group were supposed to watch a pedagogical film, and the students in the second group watched an authentic movie.

In each treatment session, the researcher asked the students to watch the films for 30 minutes. Then, they practiced new words and talked about the part of the film they had watched. The researcher asked some questions based on the parts of the films they had watched. After four sessions working on the films with Farsi subtitles, the students received a vocabulary test with 25 multiple-choice items. Like the four first sessions, the researcher let students watch the second part of the film with English subtitles for four sessions. Then, they received another vocabulary test with 25 items. During the last four sessions, the students watched the last part of the film with no English or Farsi subtitles. The researcher took advantage of many different techniques to teach new vocabulary items. For instance, he provided the students with synonyms and antonyms of a word, or asked them to look up the new vocabulary in a dictionary. The researcher asked the students to practice and revise the new vocabulary items. Then, he asked them to discuss the film they had watched. During the discussion, the students were asked to use the new vocabulary items they had learned through the film. At last, by using One-way ANOVA, the researcher tried to compare the results of tests to each other to identify the importance of films subtitles. Moreover, to identify which one is more effective Tuckey test was used. Finally, to identify the effects of both pedagogical and authentic films on EFL learners' vocabulary learning, the researcher administered an Independent Samples $t$-test to each group.

\section{Results}

The mean scores of each student in two tests were calculated, and then the researcher applied the Independent Sample ttest. The results of the t-test are illustrated in Table1.

Table 1. Statistics for the pedagogical and authentic films

\begin{tabular}{lcccc}
\hline & $\mathrm{N}$ & Mean & Std. Deviation & Sig. \\
\hline Group 1(Pedagogical) & 15 & 18.40 & 2.465 & .024 \\
\hline Group 2(Authentic) & 15 & 20.56 & 3.674 & \\
\hline
\end{tabular}

As shown in Table 1, the computed significance was equal to .024 which was smaller than the significance level. There was also a statistically significant difference between the pedagogical and authentic groups in terms of their effects on the Iranian EFL students' vocabulary learning.

One-way ANOVA was used to identify the impact of pedagogical films with and without English and Farsi subtitles on the Iranian EFL students' vocabulary learning. One-way ANOVA was done on the test scores in three different modes of subtitles. Table 2 showed that the impacts of pedagogical films with English and Farsi subtitles and without any subtitles on Iranian EFL vocabulary learning was significant.

Table 2. The results of pedagogical films

\begin{tabular}{lccccc}
\hline & Sum of Squares & df & Mean squares & F & Sig. \\
\hline Between Groups & 83.534 & 2 & 41.571 & 7.459 & .003 \\
\hline Within Groups & 327.453 & 27 & 5.674 & & \\
\hline Total & 410.987 & 29 & 47.245 & & \\
\hline
\end{tabular}

The results of Posthoc Thkey showed the statistical difference between the groups received film with English subtitles and the groups received no subtitles. Moreover, there was a significant difference between the group received the film with Farsi subtitles and the group received film with English subtitles. The results are shown in Table 3.

Table 3. The results of authentic films

\begin{tabular}{llllll}
\hline & Sum of Squares & df & Mean squares & F & Sig. \\
\hline Between Groups & 148.325 & 2 & 95.545 & 7.343 & .000 \\
\hline Within Groups & 438.24 & 27 & 4.377 & & \\
\hline Total & 585.565 & 29 & 99.922 & & \\
\hline
\end{tabular}


As depicted in Table3, the results of One-way ANOVA revealed that the difference between the impacts of authentic films with English and Farsi subtitles and no subtitles was significant. A post-hoc Tuckey test was done to identify which group performed better. A significant difference was seen between Farsi and English subtitles. However, the films with English subtitles were more effective. Moreover, a significant difference was between the performance of the students who received the films with English subtitles and the students who received the films with no subtitles.

\section{Discussion and Conclusion}

The outcomes of the present study indicated that films with English subtitles are very effective and help students to improve their vocabulary knowledge. They also showed that even a part of film can be effective for improving vocabulary (Zarei, 2008, Zhang \& Wu, 2011a, 2011b). The comparison of the performance of both pedagogical and authentic groups revealed that the students in authentic group had better performance and they were more successful in vocabulary learning.

The findings of this study show that films can make the students active and can also decrease the anxiety among the students. As a result, it can help students to acquire the foreign language more easily (Hayati \& Mohammadi, 2009). In addition, the results of other studies also show that using subtitles are effective and helpful in learning a foreign language (Alipour, Gorjian \&Gholampour Kouravand, 2012).

\section{References}

Chapple, L., \& Curtis, A. (2002). Content based instruction in Hong Kong: Student response to film. System, 28, 419433.

Danan, M. (2004). Captioning and subtitling: Undervalued Language Learning Strategies.Meta, 49(1), 67-77.

Gorjian, B., Pazhakh, A. R., \& Parang, K. An investigation on the effect of critical thinking (CT) instructions on Iranian EFL learners' descriptive writing: A case of gender study. Advances in Asian Social Science, 1(1), (2012), 114-118.

Gorjian, B., Pazhakh, A. R., \& Naghizadeh, M. (2012). Comparative study of conjunctive adverbials (CAs) in native researchers' (NRs) and nonnative researchers' (NNRs) experimental articles. Advances in Asian Social Science, 1(2), 224-247.

Gorjian, B., Alipour, M., \& Saffarian, R. (2012). The effect of multisensory techniques on reading comprehension among pre-intermediate EFL learners: The case of gender. Advances in Asian Social Science, 1(2), 192-196.

Hayati, A. \& Mohammadi, F. (2009). The effect of films with and without subtitles on listening comprehension of EFL learners. British Journal of Educational Technology, 42(1), 181-192.

Kim, D., \& Gilman, D. A. (2008). Effects of Text, Audio, and Graphic Aids in Multimedia Instruction for Vocabulary Learning. Educational Technology \& Society, 11(3), 114-126.

Koolstra, C. M. \& J. W. J. Beentjes. (1999). Children's vocabulary acquisition in a foreign language through watching subtitled television programs at home. Educational Technology Research and Development, 47(1), 51-60.

Mishan, F. (2005).Designing authenticity into language learning materials. Portland: Intelect Ltd.

Reese, S. D., \& W. R. Davie. (1987). Captioning effects of television news learning. Paper presented to the RadioTelevision Journalism of the Association forEducation in Journalism and Mass Communication Annual Conference, San Antanio, Texas.

Sharpe, P. J. (2004). How to prepare for the TOEFL. New York: Barron's Educational Series, Inc.

Solsow, J., \& Ascher, A. (2007). Top notch series. London: Longman.

Stewart, M. A., \& I. Pertusa. (2004). Gains to language learners from viewing target language closedcaptioned films. Foreign language Annals, 37(3), 437- 447.

Sydorenko, T. (2010).The effects of captioning videos used for foreign language listening activities. Language Learning and Technology, 14(1), 65-86.

Talavan, N. (2007). Using subtitles in a multimedia environment to enhance listening comprehension for foreign language students of English. Proceedings VI International AELFE Conference. Lisbao, ISCAL, 452- 458.

Thornbury, S. (2004). How to teach vocabulary. Longman: Pearson Education Limited.

Yoshi \&Flaitz. (2002). Second language vocabulary retention: the effects of text and picture annotation types. CALICO Journal, 20(1), 33-58.

Zarei (2008).The effect of bimodal, standard, and reversed subtitling on L2 vocabulary recognition and recall.SID Journal, 5(1), 65-84.

Zhang, Y, \& Wu, L. (2008). Weights optimization of neural network via improved BCO approach. Prog., Electromagn. Res., 83, 185-198.

Zhang, Y, \& Wu, L. (2011a). A novel algorithm for APSP problem via a simplified delay pulse coupled network. Journal ofComputational Information Systems, 7 (3), 737744.

Zhang, Y, \& Wu, L. (2011b). A hybrid TS-PSO optimization algorithm. Journal of Convergence Information Technology, 6 (5), 169-174.

Zhang, Y, Wang, S, Wu, L, \& Huo,Y. (2011). Multi-channel diffusion tensor image registration via adaptive chaotic PSO. Journal of Computers, 6 (4), 825-829.

Zhang, Y, Wu, L, Wei, \& Wang, S, L. ), (2011). A novel algorithm for all pairs shortest path problem based on matrix multiplication and pulse coupled neural network. Digital Signal Processing, 21 (4), 517-521. 